\title{
Variation and extrema of human interpupillary distance
}

\author{
Neil A. Dodgson ${ }^{*}$ \\ University of Cambridge Computer Laboratory, 15 J. J. Thomson Avenue, Cambridge, UK CB3 0FD
}

\begin{abstract}
Mean interpupillary distance (IPD) is an important and oft-quoted measure in stereoscopic work. However, there is startlingly little agreement on what it should be. Mean IPD has been quoted in the stereoscopic literature as being anything from $58 \mathrm{~mm}$ to $70 \mathrm{~mm}$. It is known to vary with respect to age, gender and race. Furthermore, the stereoscopic industry requires information on not just mean IPD, but also its variance and its extrema, because our products need to be able to cope with all possible users, including those with the smallest and largest IPDs. This paper brings together those statistics on IPD which are available. The key results are that mean adult IPD is around 63 mm, the vast majority of adults have IPDs in the range $50-75 \mathrm{~mm}$, the wider range of $45-80 \mathrm{~mm}$ is likely to include (almost) all adults, and the minimum IPD for children (down to five years old) is around $40 \mathrm{~mm}$.
\end{abstract}

Keywords: interpupillary, IPD, eye separation, stereoscopic

\section{INTRODUCTION}

Interpupillary distance (IPD) is the distance between the centres of the pupils. It obviously determines the stereo separation of the two images which are combined in the brain to produce stereo perception. Mean IPD is important in the design of stereoscopic display devices and the production of stereoscopic content. Some design work, such as that which inspired this paper [1], also requires knowledge of the variation and extrema in IPD across the population. It has proved remarkably difficult to obtain scientific evidence on the variation in IPD. This paper pulls together the evidence which is available and summarises my findings.

\section{PRINCIPAL FINDINGS}

Mean IPD depends on the characteristics of the population from which the data is drawn. Mean IPD is statistically significantly different between the two genders, between certain racial groups, between near and far viewing, and between certain age groups. Mean and median IPD for the adult human population both appear to lie somewhere near $63 \mathrm{~mm}$. With regard to extrema: the vast majority of adults lie within the range 50 to $75 \mathrm{~mm}$. There are several cases of people outside this range so, to ensure that all adults are accommodated, I recommend a range of 45 to $80 \mathrm{~mm}$, although there is at least one known case of a 15 year old female with an IPD of $43 \mathrm{~mm}$ [2,3], which is outside even this extended range. If you wish to take into account children down to age five, then the minimum should be reduced to $40 \mathrm{~mm}$. In the (unlikely) event that you need to consider newborn babies, the minimum should be reduced still further, perhaps as low as $30 \mathrm{~mm}$.

\section{DATA SOURCES}

I have located a variety of sources which contain statistics on IPD. Section 7 summarises these statistics. I also have had access to the ANSUR database of physiological measurements of 3982 subjects [4]. I perform a simple statistical analysis of this database in Section 5, looking in particular at the dependence of IPD on gender, racial group, and age. The following section begins the discussion by presenting my initial investigations. These illustrate the difficulty of producing definitive values for the mean and extrema of IPD.

\footnotetext{
* e-mail: nad@cl.cam.ac.uk

Copyright 2004 SPIE and IS\&T. This paper is published in Proc. SPIE vol. 5291 and is made available as an electronic preprint with permission of SPIE and IS\&T. One print or electronic copy may be made for personal use only. Systematic or multiple reproduction, distribution to multiple locations via electronic or other means, duplication of any material in this paper for a fee or for commercial purposes, or modification of the content of the paper are prohibited.
} 


\section{INITIAL INVESTIGATIONS}

My search for data on IPD led to the discovery that there is remarkably little agreement even on the value of mean IPD. I have seen mean IPD quoted as 58, 60, 61, 62, 63, 63.5, 64, 65, 66, and $70 \mathrm{~mm}$. My survey of IPD measurements (Sections 5 and 7) shows that all of these, with the possible exception of $70 \mathrm{~mm}$, are plausible for different genderspecific and race-specific subsets of the human population. As an example, consider Hofstetter's study of adult white males from the United States of America [5]. For this sample set, the mean is between 65 and $66 \mathrm{~mm}, 90 \%$ of subjects lie between 60 and $70 \mathrm{~mm}$, and $99.8 \%$ between 55 and $75 \mathrm{~mm}$. However, these statistics are only valid for adult white American males. The analysis in Section 5 shows that we certainly cannot assume that adult white American males are a statistically unbiased subset of the human population. Hofstetter recognises this: for example he asserts that the adult white American female mean will be 2 to $3 \mathrm{~mm}$ less than the male mean, and that it is probable that about $2 \%$ of adult white American females have an eye separation less than $55 \mathrm{~mm}$.

Evidence that different racial groups have different mean eye separations is obvious from the analysis in Section 5 . As a simple example, a survey of healthy Congolese children [6] gave a mean of $69.2 \mathrm{~mm}$ and standard deviation of $3.9 \mathrm{~mm}$ for the oldest age group (11 children aged 15-18 years). This is a statistically significant difference (at $98 \%$ confidence level) from Hofstetter's results.

With regard to change in IPD with age, Aslin and Jackson say that IPD increases by $60 \%$ from a mean of $40 \mathrm{~mm}$ in the neonate to a mean of about $65 \mathrm{~mm}$ in the adult [7]. Most of this change occurs in the first year of life [8] as can be seen in Figure 1 [3]. There is some evidence that IPD continues to increase slightly up to age 30 [2].

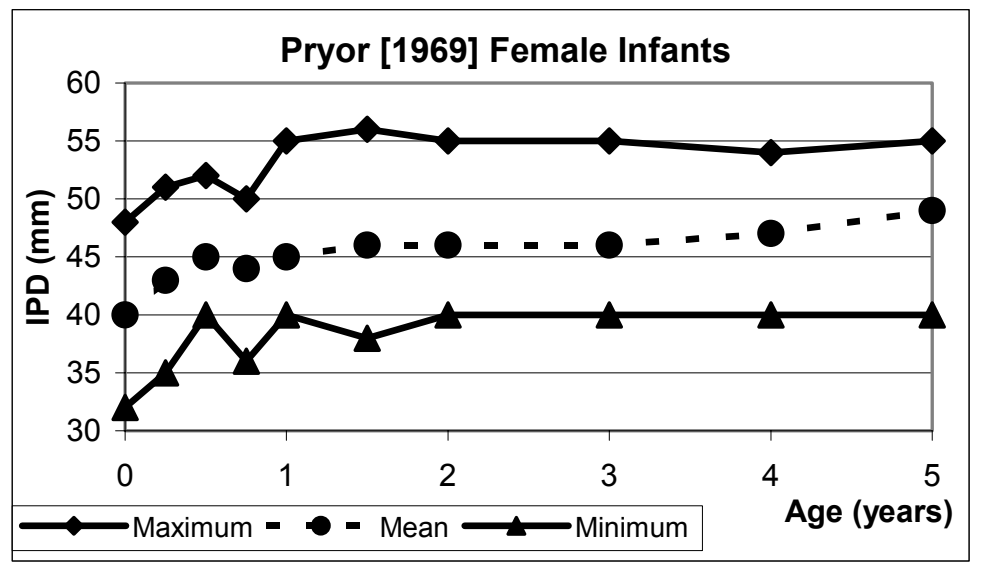

Figure 1: Data from Table V of Pryor [3] showing minimum, mean and maximum IPD for sample sets of children at ages: new born, 3,6 and 9 months, 1 year, 11/2, 2, 3, 4, and 5 years.

Further examples of figures quoted in the literature are means of $64 \mathrm{~mm}$ (male) and $62 \mathrm{~mm}$ (female) [9], means of $61 \mathrm{~mm}$ (male) and $58 \mathrm{~mm}$ (female) with a standard deviation of $4 \mathrm{~mm}$ for both genders [10], and a mean of $63 \mathrm{~mm}$ with "variation" of $8 \mathrm{~mm}$ [11] (by "variation" I assume that the author is referring to the overall range ${ }^{\dagger}$, which would thus be 55-71 mm). Waack quotes $63.5 \mathrm{~mm}$ as an "international standard" [12]. Unfortunately, he gives no reference for which international standards organisation has set this as a standard. The figure $63.5 \mathrm{~mm}$ seems rather too precise and I find it suspicious that it is exactly equal to 2.5 inches. Waack also quotes the range of IPD to be 50-70 mm, which excludes the top $2.5 \%$ of Hofstetter's subjects and the top 3.4\% of the ANSUR subjects (see Section 5).

While the confusion over the mean is one problem, I am also interested in acquiring accurate data on the distribution and the extrema of human eye separation. It is clear that human eye separation cannot be drawn from a true normal distribution, with infinitely long tails, and that there must be some extrema outside which there will be no examples in the human population. Manufacturers of binoculars and stereo microscopes have had to deal with these extrema for several decades. It is instructive to consider the range of adjustments quoted for stereo microscopes. Zeiss quote 55$75 \mathrm{~mm}$ for their Stemi SV range; Meiji Techno EMZ 54-75 mm; Wolfe Selectra 51-73 mm; Bluelight XTS 55-75 mm

\footnotetext{
† It is unlikely that this use of the term "variation" could refer to standard deviation, because the standard deviation for IPD is around $3 \mathrm{~mm}$ in all of the studies I have seen.
} 
[these values are all taken from the companies' websites]. Zeiss and Bluelight (the narrowest range of values) exclude the outer $0.2 \%$ of Hofstetter's sample and the outer $0.7 \%$ of the ANSUR sample (see below), while Meiji (the widest range) excludes about $0.5 \%$ of the ANSUR sample. Note that $0.5 \%$ represents one adult in two hundred who is unable to adjust the microscope to fit. If children use these microscopes then a larger proportion will be unable to set the IPD to be small enough to use (see Section 6).

\section{ANSUR DATABASE}

The ANSUR database [4] contains a wide range of physiological data on 3982 subjects aged 17 to 51 . I chose to consider IPD grouped by gender, race and age. I first removed a few subjects whose IPD had not been measured. This left a raw data set of 3976 subjects. Figure 2 graphs the overall distribution of IPD, while Table 1 gives the overall statistics for all subjects. In all cases IPD is measured to the nearest millimetre.

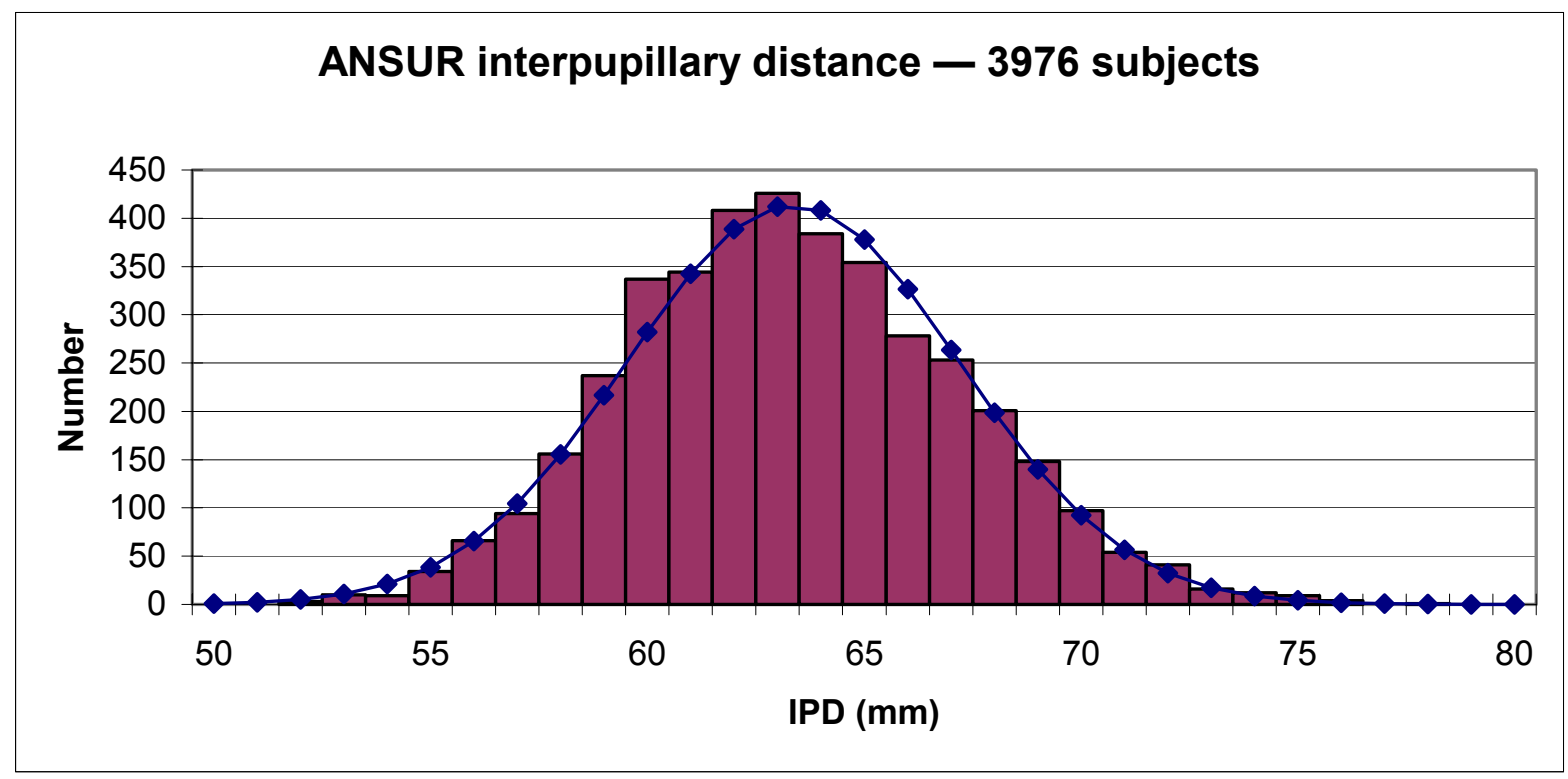

Figure 2: Distribution of IPD for the entire ANSUR database. The bars show the number of subjects with each IPD (measured to the nearest millimetre). The dotted line shows the normal distribution with the same mean and standard deviation, for comparison.

\begin{tabular}{|c|c|c|c|c|}
\hline & $\begin{array}{l}\text { IPD } \\
(\mathrm{mm})\end{array}$ & $\begin{array}{c}\text { Age } \\
\text { (years) }\end{array}$ & $\begin{array}{l}\text { Head } \\
\text { breadth } \\
(\mathrm{mm})\end{array}$ & $\begin{array}{l}\text { Ratio of } \\
\text { head } \\
\text { breadth to } \\
\text { IPD }\end{array}$ \\
\hline Minimum & 52 & 17 & 126 & 1.861 \\
\hline Mean & 63.36 & 26.63 & 147.66 & 2.337 \\
\hline Maximum & 78 & 51 & 173 & 2.818 \\
\hline St'd Dev. & 3.832 & 6.237 & 6.267 & 0.136 \\
\hline Median & 63 & 25 & 147 & 2.338 \\
\hline Mode & 63 & 20 & 147 & \\
\hline
\end{tabular}

Table 1: Overall statistics for the ANSUR database of 3976 subjects.

\subsection{Gender}

Table 2 shows the statistics for IPD for the two genders, with Figure 3 showing the distribution for female subjects and Figure 4 showing the distribution for male subjects. A $t$-test can be used to ascertain whether the male and female means are significantly different. For the ANSUR database, the $t$-value comparing the two genders is 20.2, which is significant 
at the $99 \%$ level (in fact, this $t$-value is so large, that the probability that the male and female subjects are drawn from populations with the same mean is less than $10^{-85}$ ).

\begin{tabular}{lrr} 
Gender & Male & \multicolumn{2}{c}{ Female } \\
\hline Number & 1771 & 2205 \\
Minimum & 52 & 52 \\
Mean & 64.67 & 62.31 \\
Maximum & 78 & 76 \\
St'd Dev. & 3.708 & 3.599 \\
\hline
\end{tabular}

Table 2: ANSUR IPD statistics by gender. All IPD measurements are in millimetres.

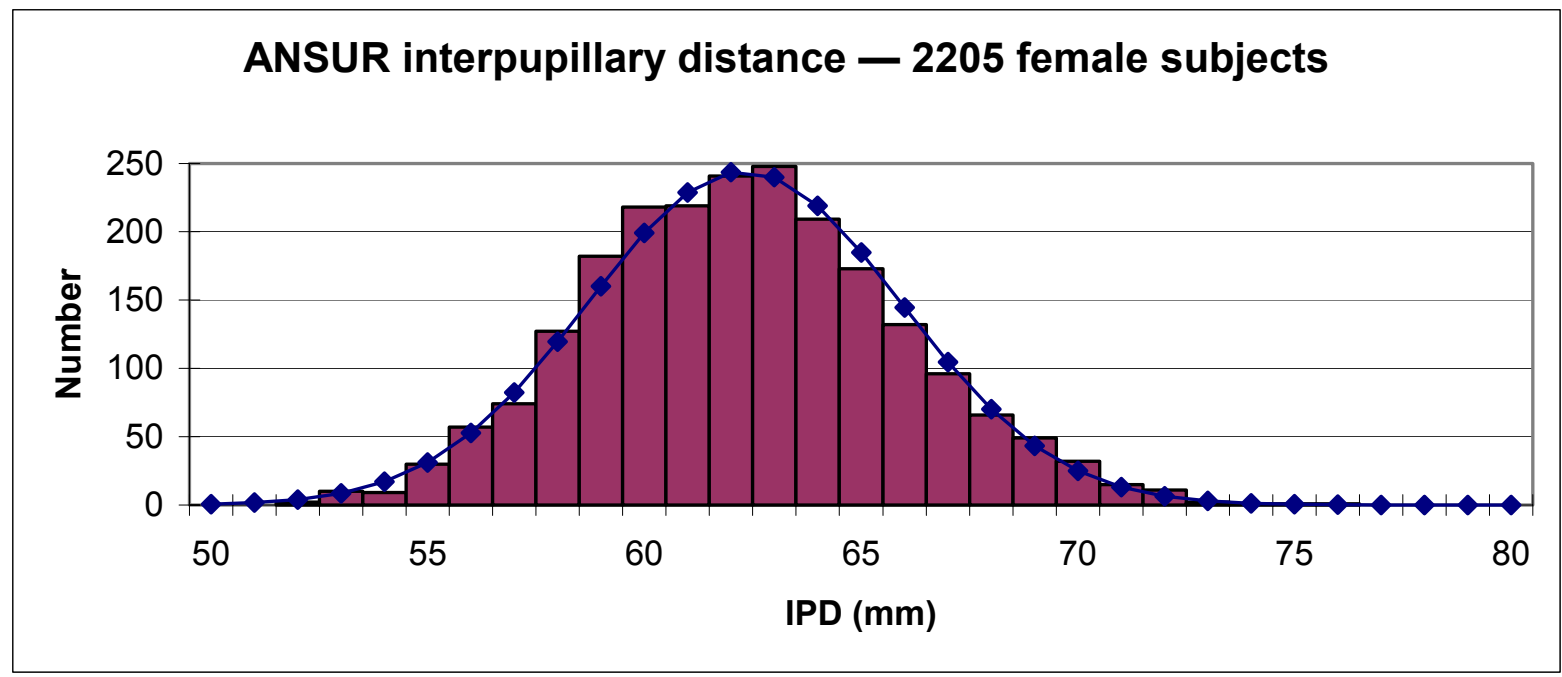

Figure 3: ANSUR female subjects only. The bars show the number of subjects with each IPD (measured to the nearest millimetre). The dotted line shows the normal distribution with the same mean and standard deviation, for comparison.

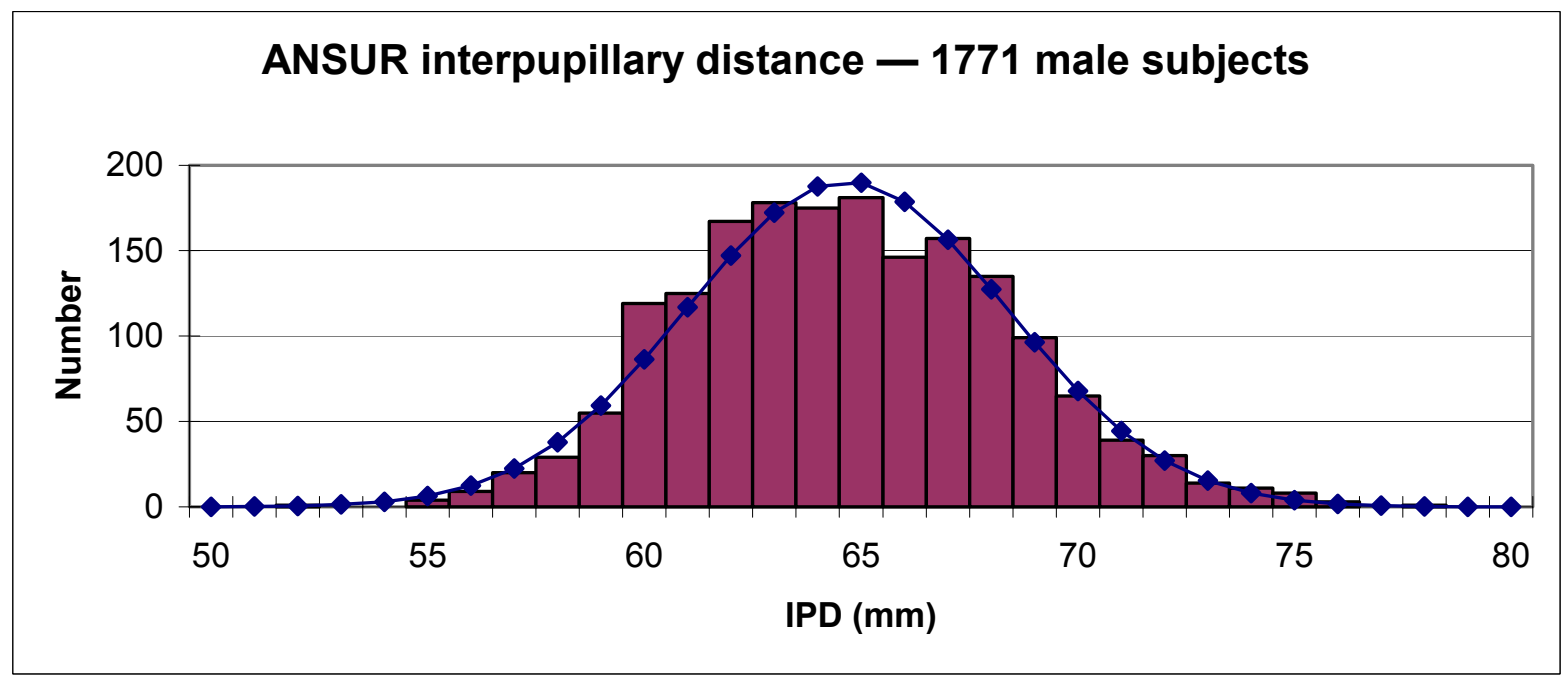

Figure 4: ANSUR male subjects only. The bars show the number of subjects with each IPD (measured to the nearest millimetre). The dotted line shows the normal distribution with the same mean and standard deviation, for comparison. 


\subsection{Race}

The ANSUR database also gives a racial group for each subject (white, black, Hispanic, Asian/Pacific Islander, American Indian, and others). Table 3 gives the summary statistics for these racial groups. Table 4 shows the $t$-test comparisons between racial groups, which show that there are significant differences between certain groups. More evidence for difference between racial groups can be obtained from Pheasant [13]. He provides statistics on median head breadth for a range of racial groups (see Table 5), showing that there is some variation between racial groups. As shown in Table 1, head breadth is obviously closely related to IPD. This variation in head breadth between racial groups is likely to be reflected in IPD, but this must remain a conjecture as Pheasant does not supply equivalent data for IPD.

\begin{tabular}{lrrrrrr} 
Racial & & & & Asian/Pacific & American \\
group & white & black & Hispanic & Islander & Indian & \multicolumn{2}{c}{ other } \\
\hline Number & 2302 & 1376 & 125 & 58 & 26 & 89 \\
Minimum & 52 & 56 & 57 & 55 & 59 & 56 \\
Mean & 61.99 & 65.62 & 63.54 & 63.17 & 65.12 & 63.26 \\
Maximum & 75 & 78 & 71 & 71 & 72 & 70 \\
St'd Dev. & 3.429 & 3.489 & 3.104 & 3.146 & 4.003 & 3.315 \\
\hline
\end{tabular}

Table 3: ANSUR IPD statistic by racial groups (racial groups are those defined by ANSUR). All IPD measurements are in millimetres.

\begin{tabular}{|c|c|c|c|c|c|c|}
\hline Race & & black & Hispanic & $\begin{array}{c}\text { Asian or } \\
\text { Pacific } \\
\text { Islander }\end{array}$ & $\begin{array}{c}\text { American } \\
\text { Indian }\end{array}$ & other \\
\hline \multirow[t]{2}{*}{ white } & $t$-value & 30.735 & 5.426 & 2.824 & 3.967 & 3.542 \\
\hline & Prob. same & $<0.001$ & $<0.001$ & 0.005 & $<0.001$ & $<0.001$ \\
\hline \multirow[t]{2}{*}{ black } & $t$-value & & 7.079 & 5.775 & 0.637 & 6.490 \\
\hline & Prob. same & & $<0.001$ & $<0.001$ & 0.524 & $<0.001$ \\
\hline \multirow[t]{2}{*}{ Hispanic } & $t$-value & & & 0.746 & 1.887 & 0.638 \\
\hline & Prob. same & & & 0.456 & 0.061 & 0.524 \\
\hline Asian or & $t$-value & & & & 2.190 & 0.159 \\
\hline Pacific Islander & Prob. same & & & & 0.031 & 0.874 \\
\hline American & $t$-value & & & & & 2.159 \\
\hline Indian & Prob. same & & & & & 0.033 \\
\hline
\end{tabular}

Table 4: $t$-test comparisons between racial groups. For each comparison I show the $t$-value and the associated probability that the data for the two groups is drawn from the same distribution. A grey background to the values indicates that the two groups are not statistically significantly different at the $99 \%$ confidence level. A white background indicates that the two groups are statistically significantly different at the $99 \%$ confidence level.

\begin{tabular}{lrr} 
Racial group & \multicolumn{2}{c}{ Head breadth $(\mathrm{mm})$} \\
Male & Female \\
\hline Indian & 145 & 135 \\
Swiss & 150 & 140 \\
French & 150 & 140 \\
British & 155 & 145 \\
Swedish & 155 & 145 \\
German & 155 & 145 \\
American & 155 & 145 \\
Japanese & 155 & 150 \\
Polish & 155 & 150 \\
Hong Kong Chinese & 160 & 150 \\
\hline
\end{tabular}

Table 5: Median head breadth by racial group and gender, from reference [13]. All values are in millimetres and all are rounded to the nearest $5 \mathrm{~mm}$ 


\subsection{Age}

Finally, it is possible to analyse IPD for different age groups. Figure 7 (on the following page) shows the distribution of ages and the mean IPD for each age. The graph appears to show that mean IPD increases slightly with age, at least between 20 and 40 years old. However, it is important to check that such an appearance is statistically significant. Figure 5 summarises a set of $t$-tests taken by comparing the age groups at 20,30 and 40 years old against every age group. This shows that there is some statistical evidence that IPD continues to increase in adulthood for the ANSUR sample set, although the increase is small. Indeed, the increase is unlikely to be as dramatic as Figure 7 and Figure 5 appear to indicate, because the proportion of men in the sample is noticeably different for ages 35 and above compared with ages 34 and below. Figure 6 shows the details. Figure 8 shows the same analysis for the more uniform subset of the 1134 white females in the ANSUR database. This gives a little evidence that there is some change with age, notably that the 40 year old white females are statistically significantly different to white females in their early twenties.

Evereklioğlu et al. [2] show that, in their sample set of 3448 subjects, IPD increases markedly up to age 19 in males and up to age 14 in females, reflecting the earlier maturation of females compared with males. They refer to evidence in the literature that IPD continues to increase slightly up to about age 30, which is consistent with the slim evidence from the ANSUR database, however their own data does not provide any statistically significant differences (at the $99 \%$ confidence level) between any of the male age groups over the age of 18 nor between any of the female age groups over the age of 15 , with the exception of a statistically significant difference between the 16-18 year old and the 31-40 year old female groups.

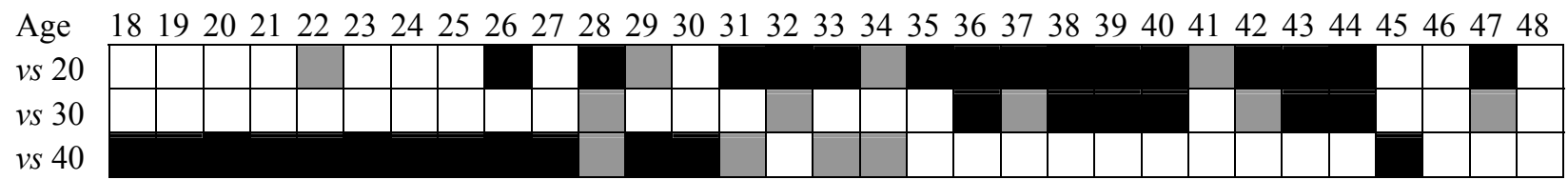

Figure 5: Summary of $t$-test results between every age group and each of the three age groups for 20, 30 and 40 years old. A black square indicates that the age groups have statistically significantly different mean IPDs at the $99 \%$ confidence level; a grey square indicates a $95 \%$ confidence level; a white square indicates that the confidence level is below $95 \%$. However, the comparisons for ages of 35 and over are likely to have a gender-induced bias, as the proportion of males in the sample is dramatically different for age groups above 35 compared with age groups below 35 (see Figure 6).

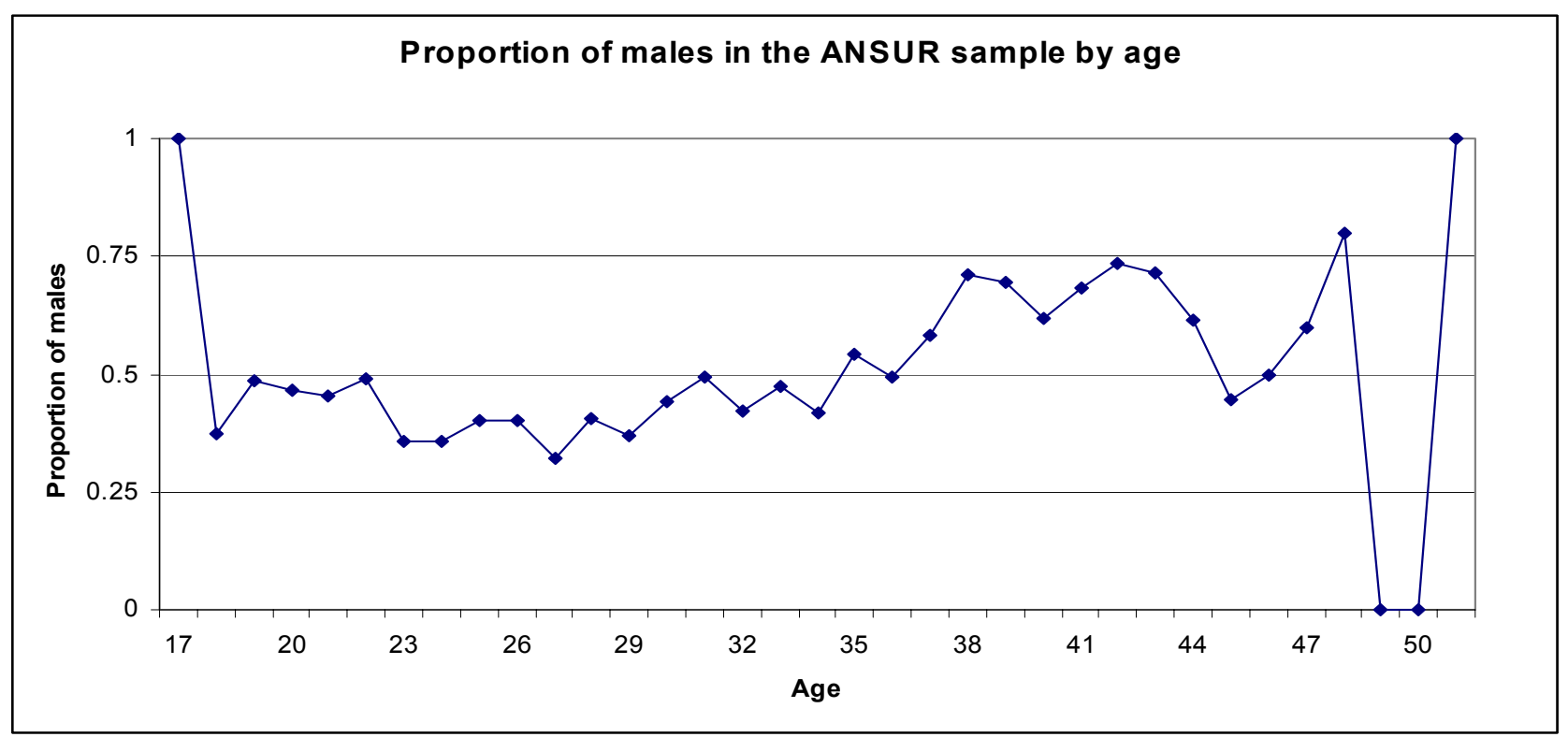

Figure 6: The proportion of males in the ANSUR sample by age. Given that we know that males and females have a statistically significantly different mean IPD, this shows that the results in Figure 5 should be taken with a pinch of salt, as there is correlation between age and gender for this particular sample set. The proportion of males in the whole sample is $0.445(1771 / 3976)$. 

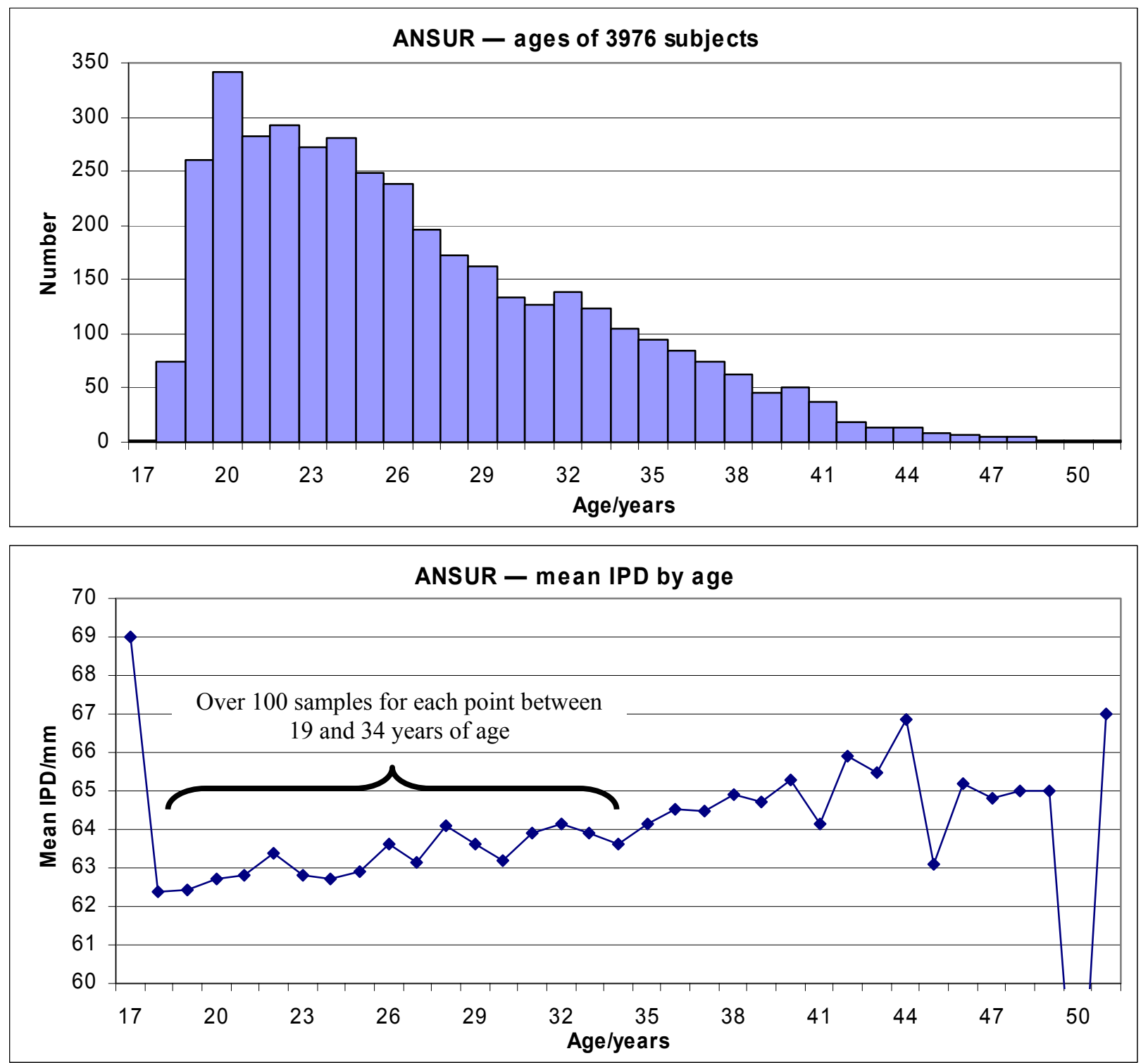

Figure 7: The bottom graph shows mean IPD for each age group within the ANSUR data. The top graph shows the number of subjects within each age group and, therefore, indicates the likely accuracy of the data in the bottom graph. For example, there is only one subject of age 17; he has an IPD of $69 \mathrm{~mm}$, but this is unlikely to be the mean IPD for all 17 year olds; whereas there are over 300 subjects aged 20 , so their mean IPD $(62.59 \mathrm{~mm})$ is much more likely to be close to the population mean. The ANSUR database has over 100 samples for each age in the range 19-34.

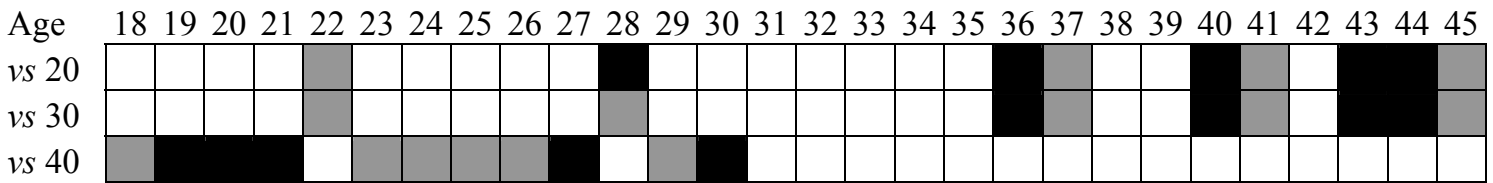

Figure 8: The same as Figure 5 but for the white female subjects only (1134 subjects). 


\subsection{Summary of ANSUR statistics}

IPD in the ANSUR database ranges from 52 to $78 \mathrm{~mm}$, with mean, median and mode all at or near $63 \mathrm{~mm}$. There are statistically significant differences between the two genders and between certain racial groups. There is some evidence that IPD continues to increase into early adulthood.

\section{CHILDREN}

Certain applications of stereoscopy are used by both adults and children. The principal examples are in entertainment: video games, theme park rides, and movies. It is therefore instructive to consider how IPD changes as a child grows. In particular, I am interested to ascertain the minimum IPD for those children who may use autostereoscopic video game machines, as children's minimum IPD is almost certainly lower than adult minimum IPD. My main sources for information on children's IPD are Fledelius and Stubgaards's study of ages 5 to adult [14], and Pryor's study of ages 0 to 15 [3].

The most dramatic increase in IPD occurs in the first year of life [8]. Pryor [3] has measured this increase. Figure 1 shows her results for female infants (who have smaller IPDs than males). Based on this data, any stereoscopic system which needs to accommodate neonates will need to be able to cope with IPDs as low as $32 \mathrm{~mm}$.

It is unlikely that there will be a need for a stereoscopic display device for serious use by anyone below the age of five. Figure 10 (on the following page) summaries Fledelius and Stubgaard's results for children over the age of five. They show that IPD continues to increase from early childhood to late teens. Pryor [3] considers 6-15 year olds, both male and female, from both California and Mexico. Of these, the female Californians have the lowest IPDs, and the statistics for this group are summarised in Figure 9 (below). The lowest IPD I have found for anyone over the age of five can be seen in this Figure, where one subject had an IPD of $40 \mathrm{~mm}$.

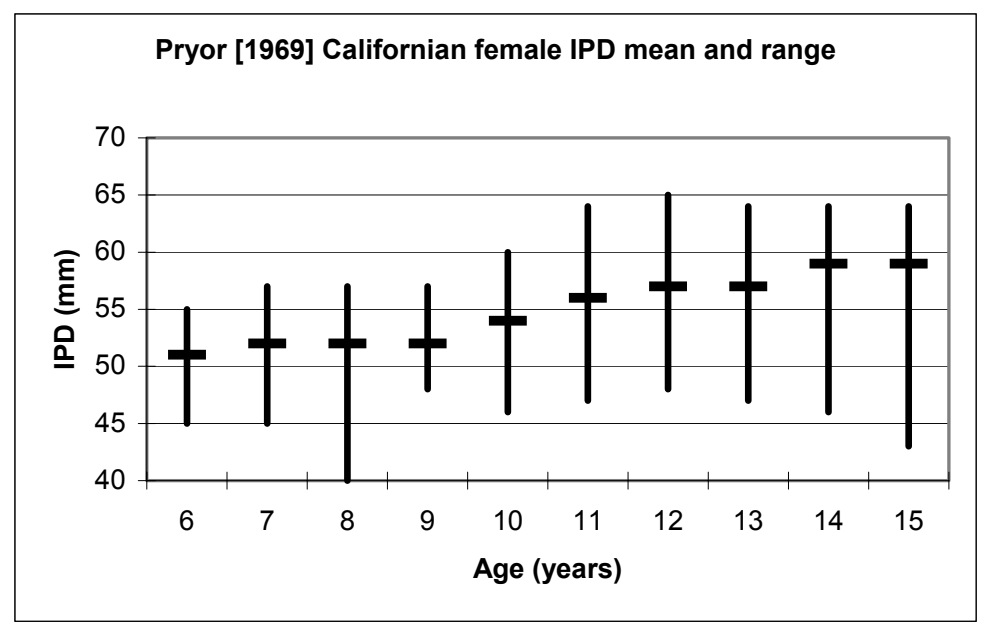

Figure 9: Data from Tables II and V of Pryor.

Note the minimum IPD for age eight: $40 \mathrm{~mm}$. This is the smallest IPD I have seen for any child above the age of five. 

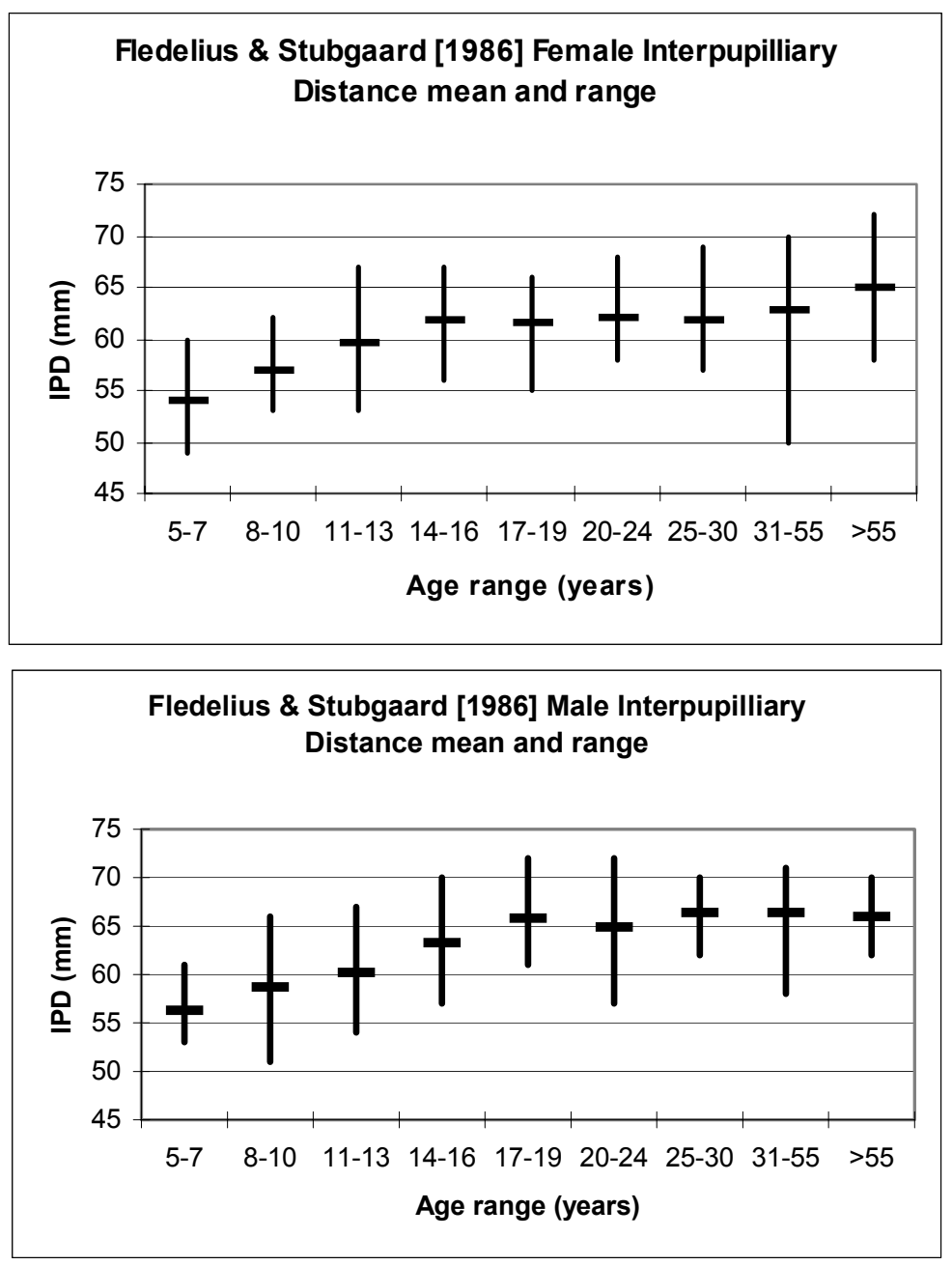

Figure 10: Data from Tables 2 and 3 of Fledelius and Stubgaard [14] 


\section{SUMMARY OF STATISTICAL RESULTS}

Table 6 summarises the statistics from all of the data sources which I have found. Evereklioğlu et al's study [2] is particularly interesting because it summarises the results of six earlier studies. Their study also shows that there is a statistically significant difference between near and far IPD. In the study, near IPD is measured with the viewer converging at $40 \mathrm{~cm}$; far IPD with the viewer converging at infinity. They show that near IPD is about $3 \mathrm{~mm}$ less than far IPD. I believe that all of the values shown in Table 6 are for far IPD, so the minima in that Table need to be reduced by roughly $3 \mathrm{~mm}$ to get values which account for near viewing as well as distant viewing. This means that (discounting the anomalous $43 \mathrm{~mm}$ measurement for one 15 year old subject [2,3]) the range of IPD from Table 6 is $47-78 \mathrm{~mm}$. Adding a couple of extra millimetres at either end of the range to take account of any even more extreme examples and to make these numbers multiples of 5, gives a range of $45-80 \mathrm{~mm}$. It is unlikely that there are many (any?) fully-grown adults with an IPD outside this range. If you find this range too wide then I expect that the narrower range of 50-75 mm will include the vast majority of adults, as stereo microscope manufactures already explicitly assume in the adjustment ranges of their devices. Of course, designing with this narrower range does exclude some of the adult population. If children, down to age five, are to be accommodated then the minimum needs to be reduced to $40 \mathrm{~mm}$.

\begin{tabular}{|c|c|c|c|c|}
\hline Source & Min & $\begin{array}{l}\text { Median } \\
\text { or } \text { Mean }\end{array}$ & Max & Comments \\
\hline \multicolumn{5}{|l|}{ Studies of adults only } \\
\hline Dictionary of Optometry [9] & & 64 & & Male \\
\hline Dictionary of Optometry [9] & & 62 & & Female \\
\hline EDPW vol. $1[10]$ & & 61 & & Male \\
\hline EDPW vol. $1[10]$ & & 58 & & Female \\
\hline Hofstetter [5] & 55 & 65 & 75 & Male white Americans. $0.2 \%$ outside min and max \\
\hline Moffitt [11] & 55 & 63 & 71 & (see text for derivation of min and $\max$ ) \\
\hline Waack [12] & 50 & 63.5 & 70 & \\
\hline ANSUR [4] & 52 & 63 & 78 & (see Section 5) \\
\hline Evereklioğlu et al. [2] & 52 & 62.6 & 75 & Male, age $15-25$, combining all $D$ results in Table 6 \\
\hline Evereklioğlu et al. [2] & 43 & 60.8 & 74 & Female, age $15-40$, combining all $D$ results in Table 6 \\
\hline \multicolumn{5}{|c|}{ Studies which include children } \\
\hline Gupta et al. [15] & 46 & & 75 & Indians, age 3-80 \\
\hline Pryor [3] & 40 & & 69 & Female Californians and Mexicans, age $6-15$ \\
\hline Pryor [3] & 32 & & 49 & Female infants, age $0-5$ \\
\hline \multicolumn{5}{|l|}{ Stereo microscopes } \\
\hline Zeiss & 55 & & 75 & Stemi SV range \\
\hline Wolfe & 51 & & 73 & Selectra range \\
\hline Meiji & 54 & & 75 & Techno EMZ range \\
\hline Bluelight & 55 & & 75 & XTS range \\
\hline
\end{tabular}

Table 6: Summary of the minima, means, and maxima for IPD from the various sources.

\section{ACKNOWLEDGEMENTS}

Thanks to the Computer Science Department at the University of North Carolina at Chapel Hill and the School of Mathematical and Computing Sciences at the Victoria University of Wellington for their hospitality during the early work on this paper. 


\section{REFERENCES}

1. N. A. Dodgson, "The number of viewing zones required for head-tracked autostereosopic display", in preparation

2. C. Evereklioğlu, S. Doğanay, H. Er, and A. Gündüz, "Distant and near interpupillary distance in 3448 male and female subjects: final results”, Turgut Özal Tip Merkezi Dergisi 6(2):84-91, 1999 medicine.inonu.edu.tr/dergi/Contents/Volume6/Issue2/Fulltext/084-091.pdf

3. H. B. Pryor, "Objective measurements of interpupillary distance", Pediatrics 44:973-977, 1969

4. ANSUR database, 1988

C. E. Clauser, I. O. Tebbetts, B. Bradtmiller, J. T. McConville, and C. C. Gordon, Measurer's Handbook: US Army Anthropometric Survey 1987-1988, Technical Report NATICK/TR-88/043.

C. C. Gordon, B. Bradtmiller, T. Churchill, C. E. Clauser, J. T. McConville, I. O. Tebbetts, and R. A. Walker, 1988 Anthropometric Survey of US Army Personnel: Methods and Summary Statistics, Technical Report NATICK/TR89/044, United States Army Natick Research, Development and Engineering Center, Natick, Massachusetts.

5. H. W. Hofstetter, J. Am. Optometric Assoc. 43:1151-1155, 1972.

6. D. Kaimbo Wa Kaimbo, R. Ngiyulu Makuala, L. Tshilolo Mwepu, and L. Missotten, "Outer orbital distance, inner canthal distance and interpupillary distance, proptosis in children with homozygous sickle cell disease", Bulletin of the Belgian Society of Ophthalmology, 275:33-37, 2000, www.bog-sbo.org/bulletin/275_04.pdf

7. R. N. Aslin and R. W. Jackson, "Accommodative convergence in young infants: development of a synergistic sensory-motor system", Can. J. Psychol. 33:222-231, 1979.

8. J. C. Birnholz, "Ultrasonic fetal ophthalmology", Early Hum. Dev., 12(2):199-209, 1985.

9. M. Millidot, Dictionary of Optometry and Visual Science, $5^{\text {th }}$ edition, Butterworth-Heinemann, 2000, ISBN 07506-4373-0

10. The Human Factors Section, Eastman Kodak Company, Ergonomic Design for People at Work Vol. 1, Wiley, 1989, ISBN 0-471-28924-8

11. K. Moffitt, "Designing HMDs for viewing comfort", Head Mounted Displays, J. E. Melzer and K. Moffitt (editors), McGraw-Hill, 1996, ISBN 0-07-041819-5

12. F. G. Waack, Stereo Photography, 1985 (English translation of German book published by the German Stereoscopic Society), www. stereoscopy.com/library/waack-ch-3.html

13. S. T. Pheasant, Bodyspace: anthropometry, ergonomics and design, Taylor and Francis, London, 1986, ISBN 085066-340-7

14. H. C. Fledelius and M. Stubgaard, "Changes in eye position during growth and adult life as based on exophthalmometry, interpupillary distance and orbital distance measurements", Acta Ophthalmol. 64:481-486, 1986

15. V. P.Gupta, P. K. Sodhi, and R. M. Pandey, "Normal values for inner intercanthal, interpupillary, and outer intercanthal distances in the Indian population", Int. J. Clin. Pract. 57(1):25-29, Jan-Feb 2003 [abstract] 